\title{
COMPARATIVE STUDY OF DISEASE PATTERNS AND SCHOLASTIC PERFORMANCE AMONG RURAL, URBAN AND TRIBAL GOVERNMENT RESIDENTIAL HOSTEL CHILDREN OF EAST GODAVARI DISTRICT
}

\author{
${ }^{1}$ Assistant Professor, Department of Paediatrics, Rangaraya Medical College, Kakinada. \\ ${ }^{2}$ Assistant Professor, Department of Paediatrics, Rangaraya Medical College, Kakinada. \\ ${ }^{3}$ Associate Professor, Department of Paediatrics, Rangaraya Medical College, Kakinada. \\ 4 Professor \& HOD, Department of Paediatrics, Rangaraya Medical College, Kakinada. \\ 5Junior Resident, Department of Paediatrics, Rangaraya Medical College, Kakinada.
}

Sirigineedi Chandra Sekhar ${ }^{1}$, Sidhartha Kiran Gollapalli2, Amujuri Krishna Prasad ${ }^{3}$, Duggirala Manikyamba ${ }^{4}$, Nerella Jwala Vasavi ${ }^{5}$

ABSTRACT

\section{BACKGROUND}

Most of the children from tribal, rural and urban slums are found to suffer from health problems due to poor quality of life. Malnutrition continues to be major threat leading to morbidities and poor scholastic performance in these children. The welfare hostels for the children are established for weaker sections of the society as an important social welfare measure in India since long time. The data regarding the nutritional, morbidity status and scholastic performance of the children in social welfare hostels are sparse. With this background, this study was conducted to evaluate the extent and pattern of health status of school age children and their scholastic performance using a predesigned proforma.

\section{METHODS}

The study was conducted in randomly selected 3 hostels from urban, rural and tribal areas of East Godavari District. It was a cross sectional observational study.

\section{RESULTS}

Mild anaemia, poor attention and calculation ability, dental caries, refractive errors, nonspecific headaches, dermatological problems, Vitamin A deficiency were the commonly seen problems in all rural, urban, tribal hostellers.

\section{CONCLUSION}

Anaemia, dermatological problems and dental caries are more commonly observed in all, hence hygienic conditions and nutritional supplementations are to be improved. Regular de-worming program has to be successfully implemented in the hostels to decrease the prevalence of worm infestations. Poor scholastic performance can be improved by implementing skilled training programs like Pradhan Mantri Kaushal Vikas Yojana (PMKVY) in these hostels along with formal education.

\section{KEYWORDS}

Morbidity Profile, Scholastic Performance, Anaemia, Dental Caries, Refractive Errors, MMSE, Draw-A-Man Test.

HOW TO CITE THIS ARTICLE: Sekhar SC, Gollapalli SK, Prasad AK, et al. Comparative study of disease patterns and scholastic performance among rural, urban and tribal government residential hostel children of east Godavari district. J. Evolution Med. Dent. Sci. 2016;5(31):1651-1655, DOI: 10.14260/jemds/2016/389

\section{INTRODUCTION}

Health of the students should be optimum for a healthy society. Health problems of the school children varies from place to place. Children from rural and tribal areas are found to suffer from poor quality of life compared to urban areas, which shows impact on their health status and scholastic performance. In spite of several health programs in existence, malnutrition continues to be major threat affecting health of children. The welfare hostels facility for the children hailing from weaker sections of the society like scheduled castes, scheduled tribes and backward classes is an important social welfare measure in India since long time. ${ }^{1}$

Financial or Other, Competing Interest: None.

Submission 25-02-2016, Peer Review 22-03-2016,

Acceptance 28-03-2016, Published 18-04-2016.

Corresponding Author:

Dr. Nerella Jwala Vasavi,

Junior Resident

Department of Paediatrics,

Rangaraya Medical College,

Kakinada.

E-mail: jwalanerella@gmail.com

DOI: $10.14260 /$ jemds $/ 2016 / 389$
Based on this objective, the Government of Andhra Pradesh has started a large number of social and tribal welfare hostels and at present there are 2313 hostels. Data regarding morbidity profile of social welfare hostel children and their scholastic performance are sparse despite usefulness of such information in management of hostels and upliftment of these groups. $^{2}$ Therefore, present study was taken up among adolescent children of government residential hostels in rural, urban and tribal areas of Kakinada, East Godavari District, Andhra Pradesh.

\section{MATERIALS AND METHODS}

This study was a cross sectional observational study. The study was conducted from June 2014 to May 2015 in the Department of Paediatrics, Government General Hospital, Kakinada, in one among rural, urban and tribal social welfare hostels of East Godavari District respectively. After taking prior permission from hostel authorities, a total of 400 students aged between 12-15 years were selected randomly from 3 social welfare hostels one each from rural, urban and tribal areas of East Godavari District. 


\section{Inclusion Criteria}

Students studying in class 7 to 10 who were not seriously ill and were present on the day of study and were willing to participate in the study are included.

\section{Exclusion Criteria}

Students who were seriously ill or absent at the time of study and who were not willing to participate in the study. Data regarding morbidity status was collected using a predesigned, pre-tested proforma. Study material use are weighing scales, measuring tape, torch, Snellen's eye chart, stethoscope, sphygmomanometer, Sahli's haemoglobinometer. Every child was examined physically from head to toe and deviations from normal were recorded. Enquiry was made about the education and occupation of the parents, duration of stay in the hostel, practices regarding personal hygiene and occurrence of any ailment during previous two weeks. The haemoglobin estimation was done by Sahli's method. History of worm infestations was taken by asking children regarding the symptoms of infestation. Disease patterns as defined by WHO among the students were recorded. Mini Mental Scale Examination and Draw-A-Man test were used to assess the scholastic performance of hostellers.

\section{RESULTS}

- Out of 183 rural children tested, 120 (65.5\%) were found to be anaemic. Out of 146 tribal children, 93 (63.7\%) are anaemic and $50(70.5 \%)$ of urban children are anaemic. Anaemia was seen in $65.5 \%, 63.7 \%$ and $70.5 \%$ of rural, tribal and urban children respectively and was equally prevalent (Point prevalence) in all the three groups of children with a slightly higher prevalence in urban children, which was statistically not significant.

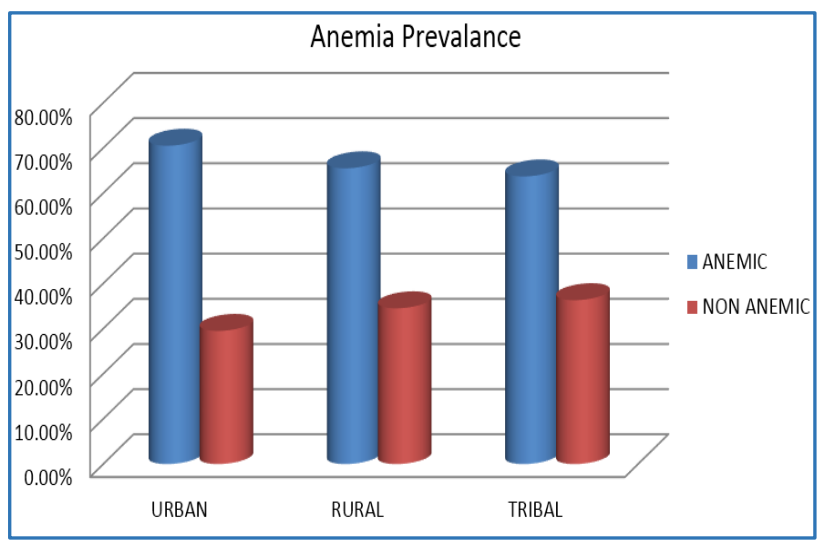

Graph 1

- Dental caries was seen in $19.1 \%, 18.3 \%$ and $18.4 \%$ of rural, urban and tribal children respectively; $0.5 \%$ of rural children had gum problems which were not present in urban and tribal children.

- $18.3 \%, 11.4 \%, 4.7 \%$ of urban, rural and tribal children respectively had refractive errors which was statistically significant.

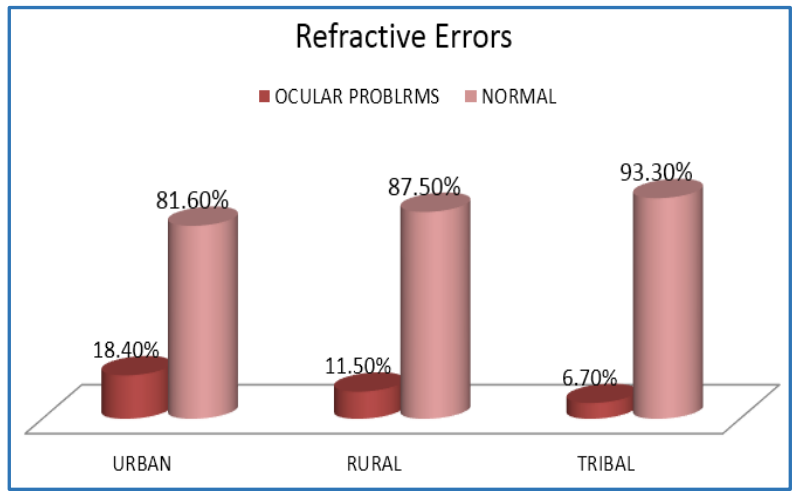

Graph 2

- 15 (3.75\%) among 400 children in all the 3 groups were found to have vitamin A deficiency manifestations; 11 (5.7\%) of 183 rural children are suffering from vitamin deficiencies, whereas 2 (2.8\%) of 71 urban study population and $2(1.2 \%)$ of 146 tribal children have vitamin deficiency manifestations. Vitamin B deficiency manifestations like cheilosis is the most prevalent of all vitamin deficiencies observed in this study. Among rural children, 4 students had Bitot spots and 2 students complained night blindness. Urban and rural children did not have any vitamin A deficiency manifestations, whereas vitamin B deficiency was equally prevalent among all the three groups, i.e. 2.75, 2.85 and $1.2 \%$ of rural, urban and tribal children respectively in the form of cheilosis.

- 19 (3.5\%) out of 400 students in all the three groups had ENT problems; $3.8 \%, 4.2 \%$ and $2 \%$ of rural, urban and tribal children had ASOM/CSOM respectively, whereas hearing impairment was seen in $2.7 \%$ and $1.4 \%$ of rural and urban children.

- $17.25 \%$ of students in 3 groups had skin problems. Among urban, tribal and rural children the prevalence was $25.4 \%, 21.9 \%$ and $15.8 \%$ respectively, which were comparable in 3 groups with no statistical significance $(\mathrm{p}=0.165)$. Pyoderma and pediculosis were more commonly observed than scabies in the present study. Scabies was more prevalent in tribal children.

- Mean MMSE scores of all the three groups are comparable with a statistical significance of $p$ value $=0.00471 .5 \%, 29.6 \%, 19.1 \%$ with IQ $41-50$ was observed in rural, urban and tribal children respectively; $53.5 \%$ and $52.1 \%$ of rural and tribal children were having IQ of 51-60 compared to $15.5 \%$ of urban children; $26.8 \%, 24.7 \%$ of rural and tribal children had an IQ of 61 70 compared to $7.1 \%$ of urban children. Overall, statistically significant low IQ was observed in urban children than tribal and rural children.

\section{DISCUSSION}

In the present study a total of 400 students aged $12-15$ years were selected randomly from three hostels, one each from rural, urban and tribal areas of East Godavari District. This study was intended to know and compare the morbidity 
profiles of students from underprivileged communities in three different areas of same district. The study was aimed to compare the scholastic performance of those children from three different places of origin.

The study also focused on availabilities regarding economy, educational facilities, awareness and other resources. Very few studies which compared the morbidity profile and scholastic performance of welfare hostel children were available. In general, it is hypothesised that tribal children will be having more health problems and scholastically backwardness compared to rural and urban children. A report of World Health Organization (2002) indicates that the Adolescence is a critical period of Growth and Development. As adolescents go through the second growth spurt in this period, it is crucial that they receive the required nutrients. In the South East Asia Region, while a large number of adolescents suffer from chronic undernutrition, those belonging to the affluent segments of society suffer from obesity. If adolescents are well nourished, they can make optimal use of their skills, energies and talents today and be responsible parents of healthy babies tomorrow.

In the present study, the leading causes of morbidity were in Rural Area-anaemia (65.5\%), dental caries (19.6\%), dermatological problems (15.8\%), refractive errors (13.5\%), non-specific headaches $(10.3 \%)$, ENT problems $(6.5 \%)$, vitamin deficiencies (5.7\%), worm infestations $(12 \%)$ and cardiovascular problems $(0.5 \%)$. In Tribal Area- anaemia (63.7\%), dermatological problems (21.9\%), dental caries (18.5\%), ocular problems (6.7\%), ENT problems $(2 \%)$, vitamin deficiency manifestations (1.2\%), non-specific headaches $(0.6 \%)$ and $8.9 \%$ of worm infestations. In Urban Area-anaemia (70.5\%), dental caries (18.4\%), ocular problems (18.4\%), skin problems (25.4\%), worm infestations (36.6\%), vitamin deficiency manifestations $(2.8 \%)$.

Morbidity profiles found among rural, urban and tribal children were shown in Table 1.

\begin{tabular}{|c|c|c|c|}
\hline Morbidity & Rural & Tribal & Urban \\
\hline Anaemia & $65.5 \%$ & $63.7 \%$ & $70.5 \%$ \\
\hline Dental Caries & $19.6 \%$ & $18.55 \%$ & $18.4 \%$ \\
\hline Vitamin Deficiencies & $5.7 \%$ & $1.2 \%$ & $2.8 \%$ \\
\hline Ocular Problems & $11.5 \%$ & $6.7 \%$ & $18.4 \%$ \\
\hline ENT Problems & $6.5 \%$ & $2 \%$ & $5.6 \%$ \\
\hline Skin Problems & $15.8 \%$ & $21.9 \%$ & $25.4 \%$ \\
\hline Worm Infestation & $12 \%$ & $8.9 \%$ & $36.6 \%$ \\
\hline CVS Problems & $0.5 \%$ & $0 \%$ & $0 \%$ \\
\hline $\begin{array}{c}\text { Non-Specific } \\
\text { Headaches }\end{array}$ & $10.3 \%$ & $0.6 \%$ & $0 \%$ \\
\hline $\begin{array}{c}\text { Table 1: Comparison of Morbidity Profile } \\
\text { Among 3 Areas of Hostel Children }\end{array}$ \\
\hline
\end{tabular}

Anaemia and dental caries being most common problem in all the three areas of children, ocular problems are more in urban children. Tribal children have more prevalence of skin problems. Rural children are suffering from skin and ocular problems next to anaemia and dental caries.

In the present study had prevalence of anaemia around $65 \%$ in all the three areas, which was comparable with Shanthi Ananthakrishnan et al. ${ }^{3}$ study (57\%), WHO Global Database on Anaemia and National survey - 2,2000.4 (58.4\%-ASIA), Akramipour $\mathrm{R}$ et al. study in Western Iran in school girls
(57.3\%). ${ }^{5}$ and M Varma et al. study in urban children of Punjab (51.5\%). 6

Present study on the consumption of the food items revealed that among the 13-15 years' age group, the intake of all nutrients was not adequate in proteins, green leafy vegetables, other vegetables, milk, fats and eggs which were below the recommended levels. In the 10-12 years' age group, the intake of all nutrients was not adequate in milk, fats, iron, green leafy vegetables and other vegetables which were below the actual requirement.

The diet survey results are comparable to the studies among children in social welfare hostels of Tirupati town by Srinivasan. ${ }^{2}$ and social welfare hostels of Nellore town by Susmitha. ${ }^{7}$ which revealed deficit intake of pulses, green leafy vegetables, milk, fats and oils, sugar and jaggery in boys and girls hostels which was below the recommended levels.

The high prevalence of dental problems may be due to inadequate oral hygiene, because not all the children were using tooth paste with brush for dental cleanliness. The reason for high prevalence in welfare hostels could be due to lack of money, either due to poverty or due to more number of children in the family, lack of knowledge about child care practices and poor oral and personal hygiene. Children experiencing dental pain or infection may have a diminished educational experience, because their discomfort may inhibit their ability to perform well while at school. The presence of refractive error in school going children affects their physical, mental and behavioural development as well. Inability to detect them at an early stage can adversely impact their learning and academic performance. In the present study, it was observed that more urban children were having refractive errors. This may be due to defective indoor light observed in urban hostels with small crowded rooms.

Refractive errors were more prevalent in urban children (18.4\%) compared to $11.5 \%$ in rural and only $6.7 \%$ of tribal children. On an average, $12.2 \%$ of present study population had refractive errors.

Present study results were comparable with Beena Sachan et al. study with $11.7 \%$ prevalence of refractive errors in Lucknow children, $12 \%$ prevalence in Sushmitha study. ${ }^{7}$ in Nellore welfare hostels, $13.65 \%$ in study done in Haryana by Seema et al. and by Ghosh et al. $14.7 \%$ prevalence in Kolkata and Vitamin deficiency present study results $(3.2 \%)$ were comparable with Srinivasan study in Tirupathi (3.2\%).2 Sivaiah et al. study in Guntur (6.7\%). ${ }^{8}$ Low prevalence was noted in comparison with Shanthi Ananthakrishnan et al. study in Tamilnadu (Vit A- 3.1\%; Vit B- 32.9\%).3 Seema Chowdary et al. study in rural Varanasi (13.7\%).

The energy supplementation given in the mid-day meals might be enhanced. The prevalence of vitamin A deficiency (3\%) observed in this study is a significant public health problem as per the criteria laid down by the WHO. Vitamin A prophylaxis program may thus have to be extended to school going children also. Other measures that may contribute to improving the health of school going children are increased energy, iron and vitamin A supplementation and periodic deworming.

\section{Skin Problems}

High prevalence of skin problems with $25.4 \%$ in urban, $21.9 \%$ in tribal and $15.8 \%$ of rural children were observed in the 
present study. On an average, $21 \%$ of study population were suffering from skin problems.

The study results are comparable with Vinod Wasnik et al. study in Vizayanagaram (16\%), Sushmitha study in Nellore (26.4\%). ${ }^{7}$ and Srinivasan study in Tirupathi (25.7\%). ${ }^{2}$ Singh et al. study in Lucknow (55.4\%) had a higher prevalence of skin problems compared to present study. Studies by Shanthi Ananthakrishnan et al. in Tamilnadu (8.7\%). ${ }^{3}$ Beena Sachan et al. study in Lucknow (3.2\%) showed low prevalence of skin problems than present study. Skin problems are mostly the result of poor personal hygiene. Periodic medical examination of the inmates and treatment facilities should be organized and morbidity of children monitored systematically.

\section{Worm Infestations}

Present study had a prevalence of worm infestations in $12 \%$ of rural children, $36.6 \%$ of urban hostellers and $8.9 \%$ of tribal children. On an average $19.1 \%$ of the study population had history of worm infestations. Present study is comparable with other studies having similar prevalence of worm infestations like $13.2 \%$ in Sushmitha study. ${ }^{7}$ in Nellore, $18 \%$ in Sivaiah et al. ${ }^{8}$ study, Srinivasan study. ${ }^{2}$ with $21.6 \%$.

Present study revealed a comparatively low prevalence of worm infestation. This may be either due to effective implementation of deworming programme in our area or actual prevalence cannot be established only by history taking. Stool examination may also be done to know the actual prevalence.

\section{ENT Problems}

In the present study, the prevalence of ENT problems were $6.5 \%$ in rural, $5.6 \%$ in urban and $2 \%$ in tribal children. Tribal children had least prevalence among the three groups. Most common problems that were observed in the present study were ear discharge [ASOM or $\mathrm{CSOM}$ ] and hearing impairment. On an average, $4.7 \%$ of the study population have some ENT problems.

Results of present study are comparable with Vinod Waski et al. study in Vizayanagaram (2.1\%). ${ }^{9}$ Shanthi Ananthakrishnan et al. study in Tamilnadu (3.1\%). ${ }^{3}$

Relatively low prevalence was observed when compared to other studies like Sivaiah et al. study in Guntur (17.1\%). ${ }^{8}$ and Singh et al. study in Lucknow (14.8\%).

\section{Scholastic Performance}

The Mini-Mental State Examination is one of the most widely used screening tests for the adult population in daily neurologic practice. Very few studies were done for comparison of normal children intellectual abilities like Rubial Alaverez et al. ${ }^{10}$ study in Spanish children.

After thorough review of literature, it was found that no studies compared the scholastic performance of rural, urban and tribal area welfare hostel children by using MMSE and Draw-A-Man test. Therefore, this may be the first study compared with the scholastic performance of the welfare hostel children by using MMSE and Draw-A-Man test.

In the present study, it was observed that $73.3 \%$ of urban children and around $50 \%$ of rural and tribal study population attained $<60 \%$ of annual marks.

Even though the mean MMSE scores were comparable in all the three groups of study population, more number of rural and tribal children were lagging in attention and calculation domain compared to urban study population. Thus, it infers that rural and tribal children in spite of better scores in annual percentages, the mathematical calculation ability was poor which may be due to formal education, lack of interest and mugging up of the lessons for passing out in examinations without proper understanding the content. The rural children are poor in orientation, registration and recall domains when compared to urban and tribal children.

Urban children in the present study were having far low IQ [77.4\% have IQ of <50] in Draw-A-Man test and also low in annual percentage marks [ $73.3 \%$ have $<60 \%$ of annual marks] compared to rural and tribal children. This poor academic performance in urban hostellers of the present study may be due to most of these children were orphans or having single parent and from very poor socioeconomic status, so they may lack parental care and vigilance.

\section{CONCLUSIONS}

Anaemia (63-70\%), dermatological problems (15-25\%) and dental caries (18 - 20\%) were more commonly observed in all the 3 groups of hostellers. To combat with these health comorbidities, the following implementations are useful.

- Good sanitation, strengthening of existing nutritional supplementation programs like Mid-Day Meal, Vitamin A supplementation, IFA supplementation and hygienic conditions need to be improved.

- Early identification of refractive errors by regular screening in hostels and immediate intervention will help to improve the vision and hence the scholastic performance of children.

- Improving the personal hygiene of hostel children by health education regarding skin care like regular bathing, not sharing towels or other goods among children and early identification and treatment will definitely decrease the skin problems.

- Regular de-worming program has to be successfully implemented in the hostels, to decrease the prevalence worm infestations along with improvement of personal hygiene measures like proper hand washing, usage of adequate footwear, avoiding unhealthy and unclean foods.

- Sanitation should be improved in the hostels like adequate water supply, proper cleaning of vegetables and other food items before cooking, good maintenance of toilets, etc.

- Similarly strengthening of regular school programs, introduction of career/skill oriented programs like PMKVY and timely management of common diseases will definitely improve the health and scholastic performance of hostel children.

- Appropriate trainings for teachers to identify the common morbidities of children at an early stage and referring to medical care will definitely improve the health and academic performance of children.

- More studies are required to assess the scholastic performance among normal children to identify the lacunae in teaching methods, so that better teaching skills and programs may be identified to improve the scholastic performance thereby increasing the creativity and productivity of children for a better nation. 


\section{REFERENCES}

1. Hall A, Bobrow E, Brooker S. Anaemia in school children in eight countries in Africa and Asia. Public Health Nutrition 2001;4(3):749-56.

2. Srinivasan K, Prabhu GR. A study of the morbidity status of the children in social welfare hostels in Tirupathi town. Indian Journal of Community Medicine 2006;31(3):1702.

3. Ananthakrishnan S, Pani SP, Nalini P. A comprehensive study of morbidity in school age children. Indian Pediatrics 2001;38(9):1009-17.

4. Editors: Bruno de Benoist. World wide prevalence of anaemia 1993-2005 WHO Global database on anaemia and national health survey-2, 2000.

5. Akramipour R, Rezaei M, Rahimi Z. Prevalence of iron deficiency anaemia among adolescent school girls from kermanshah, Western Iran. Hematology 2008;13(6):352-5.

6. Verma M, Chhatwal J, Gurmeet Kaur. Prevalence of anaemia among urban school children of Punjab. Indian Pediatrics 1999;36:1181-6.
7. Susmitha KM, Jyothi C, Prabakaran J. Morbidity pattern among the adolescent girls: a study in the social welfare hostels for scheduled castes, Nellore city, AP India. Nat J Res Com Med 2012;1(1):35-40.

8. Sivaiah T, Sitarama A. A study of health status profiles of children of welfare hostels in rural health centre, tadikonda area of Guntur district. Int J Res Health Sci 2014;2(1):26-9. [Internet] Available from http://www.ijrhs.com/issues.php?val=Volume2\&iss=Iss ue1

9. Vinod Wasnik, Sreenivas Rao B, Devkinandan Rao. A study of the health status of early adolescent girls residing in social welfare hostels in Vizianagaram district of Andhra Pradesh state. India International Journal of Collaborative Research on Internal Medicine \& Public Health 2012;4:72-83.

10. Rubial-Alvarez S, Machado MC, Sintas E, et al. A preliminary study of the mini-mental state examination in a spanish child population. J Child Neurol 2007;22(11):1269-73. 